\title{
UN SAN JUAN EVANGELISTA DEL MONASTERIO DE SAN LEANDRO: UNA NUEVA ATRIBUCIÓN PARA EL CATÁLOGO DE LA ROLDANA
}

\section{A SAINT JOHN EVANGELIST FROM THE MONASTERY OF SAN LEANDRO: A NEW ATTRIBUTION FOR THE CATALOGUE OF THE ROLDANA}

\author{
SAlvador Guijo Pérez \\ Universidad Pablo de Olavide. España \\ ORCID: 0000-0002-3768-8430 \\ salvadorguijo@hotmail.com
}

\begin{abstract}
Este artículo estudia y tiene como objetivo presentar una obra inédita que puede atribuirse a la escultora Luisa Ignacia Roldán (1652-1706). Apodada "La Roldana" fue hija y mejor discípula del gran escultor sevillano del siglo XVII, Pedro Roldán. Se trata de una talla de san Juan Evangelista, conservada en el monasterio de San Leandro de Sevilla. Esta está vinculada estrechamente con otras piezas de la mencionada autora.

Palabras clave: Barroco; escultura; Luisa Roldán; siglo XVII; monasterio de San Leandro de Sevilla; san Juan Evangelista.
\end{abstract}

This article studies and aims to present an unpublished work that can be attributed to the sculptor Luisa Ignacia Roldán (1652-1706). Nicknamed "La Roldana", she was the daughter and best disciple of the great seventeenth century Seville sculptor, Pedro Roldán. It is a carving of Saint John the Evangelist, preserved in the monastery of San Leandro in Seville. It is closely linked to other pieces by the aforementioned author.

Keywords: Baroque; sculpture; Luisa Roldán; 17th century; monastery of San Leandro of Seville; Saint John the Evangelist. 


\section{INTRODUCCIÓN}

Luisa Ignacia Roldán (1652-1706), más conocida como "La Roldana", por su filiación con el escultor Pedro Roldán (1624-1699), fue una artista destacable del Barroco sevillano. La autora tiene una obra muy dispersa. Junto con los encargos que le hicieron los organismos oficiales, como catedrales, ayuntamientos, hermandades o conventos, su creación se encuentra también diseminada en colecciones particulares. La imaginera siempre vivió de estos encargos convirtiéndose en una escultora de las más solicitadas, sobre todo, en Sevilla, Cádiz y Madrid, ciudades donde vivió y trabajó ${ }^{1}$. Los primeros años de trabajo estuvieron sumidos en el anonimato, trabajando a la sombra del taller paterno, primero, y al amparo de los contratos asumidos por su marido, Luis Antonio de los Arcos, más tarde, hasta que pudo desarrollar una labor independiente y reconocible. La eminencia de su creación artística la llevó a servir encargos regios convirtiéndose en escultora de cámara del rey, una distinción que se convertía en rareza al ser detentada por una mujer ${ }^{2}$.

En la última década, esta ha sido objeto de un creciente interés por parte de investigadores cuyos estudios han aportado claras luces a su figura. La creciente bibliografía sobre la misma, así como la adquisición de sus obras por parte de notables museos son una clara consecuencia de ello. Estudios sobre Luisa Roldán han generado considerables aportaciones ${ }^{3}$. Destacamos las investigaciones y atribuciones incluidas en el libro más actualizado publicado en el año 2018 por HallVan den Elsen ${ }^{4}$, así como los numerosos escritos del profesor Pleguezuelo5. Sin embargo, el catálogo de la misma se ha visto aumentado por un elevado número de obras de dudosa atribución que siguen aún hoy provocando una visión confusa de sus auténticas aportaciones. Con un perfil más académico este obstáculo tiende a suprimirse para conseguir elaborar un catálogo más depurado que confirme obras documentadas o de atribución segura, descarte otras más discutibles y añada alguna hasta ahora desconocida o atribuida a otro artista. En esta modesta pero necesaria tarea debe inscribirse ahora la escultura que presentamos. Se trata de una imagen de san Juan Evangelista, obra que hasta ahora había permanecido desvinculada de su catálogo y que se conserva en la clausura del convento de San Leandro de Sevilla (figura 1) ${ }^{6}$.

${ }^{1}$ García Olloqui, 2005: 92.

2 Arias Martínez, 2018: 24.

${ }^{3}$ La producción bibliográfica sobre esta artista hasta 2007 quedó recogida en Romero Torres/Torrejón Díaz, 2007. Véase también: García Olloqui, 2000.

${ }^{4}$ Hall-Van den Elsen, 2018.

${ }_{5}^{5}$ Pleguezuelo Hernández, 2010; 2011b; 2012; 2016a; 2016b, 2016c; 2016d; 2017a; $2017 b ; 2018$.

${ }^{6}$ En los orígenes y fundación del mismo véase Guijo Pérez, 2017; 2018a; 2019. Llordén, 1973. 
No conocemos la fecha exacta de la fundación de este agustino monasterio ${ }^{7}$, sin embargo, parece ser que ya existía hacia el año 1260 cuando aparece citado entre las mandas de un testamento que recogió Ortiz de Zúñiga ${ }^{8}$. Igualmente, documentos del archivo monacal $^{9}$ e historiadores ${ }^{10}$ relatan la existencia de este poco después de la conquista de Sevilla. Desde el 19 de enero de $1369^{11}$ ocupa el edificio de la collación de San Ildefonso. Entre el patrimonio artístico de este convento se encuentran multitud de imágenes con sus distintos apelativos y advocaciones. La proveniencia de la mayoría de ellas nos resulta desconocida desde el archivo monacal, pero, como bien indican testimonios expertos, podría estar en el pago de la dote de una postulante, en una dádiva a la comunidad, en el encargo del propio convento al artista o podría haber pertenecido a alguna de las seglares, damas de noble linaje o de acompañamiento que sin profesar en la orden vivían en el cenobio $^{12}$. Estas imágenes hagiográficas y también las marianas, así como las infantiles y pasionistas de Cristo tuvieron en la vida conventual un papel destacado ${ }^{13}$. Las mismas estaban presentes de forma cotidiana en las celdas de las religiosas y en las principales estancias de la clausura, alcanzando una mayor relevancia en sus respectivas onomásticas, así como en los tiempos litúrgicos de Navidad y Semana Santa $^{14}$. Nos encontramos ante esculturas de meditación desde la intimidad religiosa y objeto de piadosas reflexiones.

Con relación al referente hagiográfico que nos ocupa, el monasterio de San Leandro contó con diferentes retablos dedicados a los santos Juanes, tanto en la

${ }^{7}$ Miura Andrades, 1999: 145.

${ }^{8}$ Ortiz de Zúñiga, 1796: 236. "Subsistían ya también en toda forma los Conventos de San Pablo, San Francisco, la Merced, la Trinidad y San Leandro: para todos y para su obra hay legados píos en un testamento de este año (1260); al de San Leandro, que es su primer memoria, dice para los Cofrades de San Leandro; é á las devotas Monjas que allí moran: vese que había ya Cofradía y morada de mujeres Religiosas con título de San Leandro...".

9 Archivo del monasterio de San Leandro (AMSL). Memoria y Tradición de la venida de la milagrosa Imagen de María Santísima con el Amabilísimo título de las Virtudes, y milagros que la Señora ha obrado por mediación de esta hermosísima y devota Imagen. Sevilla, 1 de octubre de 1817, ms. Anotaciones en diferentes libros de cuentas de diferentes siglos, ms. y otros legajos del archivo conventual donde se recogen los orígenes del mismo, ms.

10 Arana de Varflora, 1789: 57. Ortiz de Zúñiga, 1796: 236. González de León, 1839: 82-84; 1844: 85-87. Madrazo, 1884: 601. Gestoso, 1889: 261. Confróntese también la sección especial del Archivo Municipal de Sevilla, que comprende los papeles y documentos adquiridos por el Excmo. Ayuntamiento de la testamentaría del Sr. Conde del Águila. Comunidades religiosas. Convento de monjas de San Leandro, tomo I, número 15, hay dos relaciones, $\mathrm{ms}$.

${ }^{11}$ Libro de Protocolo del monasterio de San Leandro (LPMSL) 1666, cuad. 1, f. 4v. Privilegio. Pedro I. 19 de enero de 1369, ms.

12 Peña Martín, 2010: 114.

13 Llompart i Moragues, 1980: 368-371.

${ }_{14}$ Peña Martín, 2009: 28. 
iglesia como en la clausura. Actualmente el templo posee dos altares encargados a Juan Martínez Montañés y trazados por Juan de Oviedo ${ }^{15}$. Previamente al retablo montañesino del Evangelista existieron otros dedicados a este mismo santo. Nos consta documentalmente que se encargó a Juan de Uceda, en 1617, un altar dedicado al Evangelista que contaba con una imagen de la Pura Concepción, una talla de san Juan de Jerónimo Hernández de un retablo anterior que ya poseía el monasterio, así como un sagrario ${ }^{16}$. Este retablo y su pintura se vendieron por Montañés al vecino convento de los Descalzos. El monasterio conservó el sagrario y la talla en el coro bajo ${ }^{17}$. El san Juan del maestro Hernández constituyó un modelo anterior al esculpido por "La Roldana", realizándose con idéntica iconografía (figura 2). Igualmente, la obra de Pacheco marcó un referente iconográfico para esta, destacando la pintura de san Juan realizada para el retablo de Francisca de León, del convento del Santo Ángel de Sevilla ${ }^{18}$, así como las pinturas de su discípulo ${ }^{19}$, Alonso Cano, para el sevillano convento de Santa Paula ${ }^{20}$.

\section{EL SAN JUAN EVANGELISTA DEL MONASTERIO DE SAN LEANDRO}

La talla de san Juan puede describirse como una imagen de un metro de altura, realizada en cedro y, aún siendo de vestir, no está dotada de candelero, sino que las formas sinuosas de la túnica se labran bajo el busto a modo de armazón. El santo tiene, por tanto, tallado el busto, las manos y los pies, así como de manera parcial, los antebrazos y las piernas. El torso ofrece un complejo volumen que finaliza en la caída de la túnica esculpida sencillamente en la madera sin policromar. En la actualidad se presenta cubierto en buena parte por ricos trajes bordados que cubren la talla, ya que se concibió para ser vestida. Tratándose de una imagen de vestir y conociéndose pocas de este tipo documentadas de la artista, debemos comparar la misma con las tres atribuidas más seguras de este estilo: la escultura firmada de Santa Clara, del convento de San Francisco de Mula (Murcia), destruida durante la Guerra Civil, así como la imagen, atribuida con fundamento, de San Francisco, en el convento de Regina Coeli de Sanlúcar de Barrameda (Cádiz) e, incluso, la del Jesús Nazareno de Sisante (Cuenca), del que se han publicado varios trabajos muy pormenorizados ${ }^{21}$. Esta

${ }_{15}$ Halcón Álvarez Ossorio/Herrera García/Recio Mir, 2009: 140-148. Citado por Guijo Pérez, 2018b: 101-111.

16 López Martínez, 1932: 204.

${ }_{17}$ Guijo Pérez, 2018b: 106-111.

18 Valdivieso González/Martínez del Valle, 2012: 54.

${ }_{19}$ Hernández Díaz, 1987: 198.

20 Wethey, 1983: 41. La pintura a la que nos referimos, San Juan Evangelista exorcizando al demonio, se encuentra en el museo del Louvre en París.

${ }^{21}$ Pleguezuelo Hernández, 2008: 18-19. 
tríada presenta rasgos en común con la imagen que nos ocupa como la concepción poderosa en la anatomía de brazos y manos, aflorando venas y tendones con gran sensibilidad en su epidermis en las figuras masculinas. Además, se repite en ellos toda una serie de sintagmas estilísticos propios de su autora en la distribución de cabellos, la configuración de ojos, cejas, boca y nariz. No presentando el dramatismo en el rostro como el último, sino la dulcificación del mismo como en la imagen de santa Clara.

Los brazos son fijos, no articulados y porta ojos de cristal originales de la época de ejecución, sin ningún tipo de modificación o intervención conservativa posterior. Respecto a las manos, su talla es cuidada y se representan con venas y tendones muy marcados, así como con falanges y nudillos resaltados, detalles que recuerdan a otras obras, como el Ecce Homo de la Catedral de Cádiz ${ }^{22}$, así como su homónimo de la iglesia de San Francisco de Córdoba.

Formalmente, la obra presenta una composición muy hermosa y frontal. El santo conserva todos sus atributos, mostrando gestualmente una iconografía, como ya hemos mencionado, desarrollada anteriormente por otros autores. Con su mano derecha se encuentra en actitud de bendecir la copa, mientras que la izquierda sostiene el cáliz del que sale una serpiente o dragón. La tradición nace a partir de una historia asociada a la biografía del santo. Estando en la ciudad de Éfeso, a Juan le ofrecieron una copa de vino envenenado, antes de beber, bendijo la bebida y el veneno salió de la copa en forma de una pequeña serpiente verde. Solo "La Roldana", en el contexto de la escultura barroca sevillana, parece haberse atrevido a dar a una imagen sagrada una gestualidad tan efusiva y espontánea, cariz que acompaña toda su obra.

El pelo de san Juan está volado hacia atrás, dejando ver las orejas como lo solían esculpir los Roldanes, como consecuencia de manejar la gubia hacia arriba. Por detrás de su cabeza se presenta su melena ondulada, como abocetada, a mechones unidos entre sí por abajo, que llegan hasta donde iría el borde del manto (figura 3). Este tipo de melenas podemos observarla en las obras documentadas, ya citadas, del Ecce Homo de la Catedral de Cádiz y del Jesús Nazareno del convento de las clarisas nazarenas de Sisante. Destacan en similitud escultórica y compositiva, sobre todo, las obras de los santos patronos Servando y Germán de la Catedral de Cádiz, tallas de 1687, a pesar de sus constatadas modificaciones posteriores ${ }^{23}$. Los santos gaditanos, así como el san Juan que estudiamos, nos muestran el aspecto de muchachos jóvenes, con cierto parecido impúber. Al igual

${ }^{22}$ Sánchez Peña, 1985-86: 330. En el interior de este Ecce Homo se encontró un documento que indicaba que había sido realizado por Luisa Roldan en compañía de su esposo Luis Antonio de los Arcos.

${ }_{23}$ Así lo ratifica José Miguel Sánchez Peña, antes de su restauración en 1993, ambas imágenes fueron intervenidas por Francisco María Mortola en 1756, así como por Francisco Fatuo y José Morillas en 1865. Véase el estudio de Sánchez Peña, 1994: 79-106. 
que en la iconografía angelical de la autora no dejan de tener cierto aire de delicadeza, que los acerca a lo femenino. La soltura de la posición de la talla muestra como la cabeza y las manos están tratadas con el habitual naturalismo de "La Roldana". La marcada impronta roldanesca se hace presente en cuanto la apreciamos detenidamente.

La imagen que nos ocupa lleva la boca cerrada no dejando, por tanto, ver los dientes, como sí podemos observar en otras obras de "La Roldana", como es el caso del san Francisco de Regina Coeli o el san Servando de Cádiz. Sin embargo, en la de san Germán, este muestra su boca cerrada imitando a tal punto la composición del san Juan de San Leandro, como si la talla que nos ocupa hubiera precedido a la realizada en Cádiz, siendo esta una evolución posterior de la primera. Comparte idéntica talla abocetada del cabello, que permite observar la huella dejada por la gubia, así como no pocos detalles anatómicos, siendo todos ellos elocuentes, incluso, la gran similitud de las orejas de ambas esculturas (figura 4). Las cejas son arqueadas, la nariz es corta y respingona con fosas nasales anchas. En boca de pequeñas dimensiones destaca un labio inferior carnoso y caído, así como el triángulo superior del mismo muy marcado. Se representa con sus mejillas y barbilla redondeadas, así como con la característica "doble papada", visible ante todo al mirar la cara de perfil ${ }^{24}$. Todas estas observaciones nos llevan con claridad a la comparación con la anterior imagen, documentada y realizada posteriormente. No hay documentos en el monasterio acerca de la citada escultura, como ya hemos mencionado, pero puede pensarse que este san Juan fue hecho en Sevilla, previamente a la etapa gaditana (1686-1688) cuando la autora vivió en Cádiz.

La policromía, que parece original, muestra una depurada técnica que contribuye a vivificar aún más el mórbido modelado del rostro juvenil del santo. El peleteado de las cejas, las mejillas sonrojadas y el vivo color rojizo de los labios contribuyen a ello. Al respecto, hay que recordar que, desde al menos su etapa gaditana, consta el trabajo de su cuñado Tomás de los Arcos en el acabado de las obras de Luisa. Esta imagen puede ser otro testimonio de sus grandes dotes como policromador, suponiendo que el mismo hubiese participado igualmente en el trabajo de esta durante su etapa sevillana.

$\mathrm{Al}$ menos en los últimos dos siglos, la imagen ha tenido una función procesional. Al carecer de documentación que lo acredite no puede certificarse, aunque tampoco negarse, que la escultura de san Juan fuera concebida desde su origen con esta misión, ya que pudo haberla adquirido con posterioridad. No basta señalar el carácter visible de talla bien acabada, así como el acusado movimiento y la perfección escultórica en todos sus flancos para vincularla indefectiblemente a dicha funcionalidad. Existen otras muchas esculturas de iguales características

${ }^{24}$ En el asunto de los ángeles véase, García Olloqui, 1983: 197. 
que nunca han llegado a procesionar. Sin duda alguna, la contemplación de la escultura, desvinculada de cualquier retablo y, por tanto, con visión perimetral (figuras 5 y 6), permite la apreciación perfecta de esta y de sus atributos, destacando la cabellera, tan perfeccionada en la parte trasera. El hecho de que esta escultura de vestir adquiriera una función procesional anual, conllevaba que durante el resto del año se custodiaba y cubría cuidadosamente en una dependencia del monasterio, condicionantes que precisamente han podido influir en su buen estado de conservación. Se trataba de una procesión claustral con un paso exuberantemente decorado para ello. Este portaba un rico patrimonio, una crestería de jarritas con azucenas plateadas recorría sus aristas, cuatro blandones, cuatro jarras para flores y, al menos, tres relicarios de plata adornaban la parihuela que era forrada, finalmente, con faldones brocados en oro. Con posterioridad, debido a la falta de religiosas y a los diferentes cambios conciliares, la talla dejó de procesionar permaneciendo oculta y retirada del culto en el monasterio hasta nuestros días. Con este estudio consideramos que el interés sobre esta atribución es reseñable, ya que tratamos de aumentar el catálogo de la escultora añadiendo una obra relacionada con una fase vital escasamente conocida, a pesar de las recientes aportaciones.

Fecha de recepción: 13 de septiembre de 2020.

Fecha de aceptación: 2 de mayo de 2021.

\section{BIBLIOGRAFÍA}

Arana de Varflora, Fermín (1789): Compendio histórico descriptivo de la muy noble y muy leal ciudad de Sevilla. Sevilla: En la Oficina de Vázquez, Hidalgo y Compañía.

Arias Martínez, Manuel (2018): "La Roldana, gusto por el detalle”. En: Descubrir el arte, 229, pp. 23-28.

García Olloqui, María Victoria (1983): "El tema de los Ángeles en la obra de Luisa Roldán”. En: Archivo hispalense: Revista histórica, literaria y artística, 202, pp. 193-202.

(2000): Luisa Roldán, la Roldana: nueva biografía. Sevilla, Guadalquivir Ediciones.

(2005): "La iconografía de San José con el Niño en dos obras de segura atribución a La Roldana”. En: Espacio y Tiempo: Revista de Ciencias Humanas, 19, pp. 91-109.

Gestoso, José (1889): Sevilla monumental y artística. Sevilla: Oficina tipográfica de El Conservador.

González de León, Félix (1839): Noticia histórica del origen de los nombres de las calles de Sevilla. Sevilla: José Morales. 
González de León, Félix (1844): Noticia histórica, artística y curiosa de todos los edificios públicos, sagrados y profanos de de esta Muy Noble, Muy Leal, Muy Heroica e Invicta Ciudad de Sevilla, y de muchas casas particulares. Sevilla: Imprenta de José Hidalgo.

Guijo Pérez, Salvador (2017): "Relación y formación del patrimonio urbano del monasterio de San Leandro de Sevilla. Siglos XIII-XVI". En: Estudios sobre Patrimonio, Cultura y Ciencias Medievales, 19, pp. 609-634.

(2018a): "Orígenes del Monasterio de San Leandro y su fusión con el emparedamiento de San Pedro de Sevilla. Siglos XIII-XVI". En: Historia. Instituciones. Documentos, 45, pp. 157-186.

(2018b): "Sobre la contratación de retablos para la nueva iglesia del monasterio de San Leandro de Sevilla. Finales del siglo XVI y primera mitad del siglo XVII". En: Archivo hispalense: Revista histórica, literaria y artística, t. CI, 306-308, pp. 91-117.

(2019): "Favores y apoyos institucionales en la consolidación de la fundación del monasterio de San Leandro de Sevilla". En: Estudios sobre Patrimonio, Cultura y Ciencias Medievales, 21, pp. 407-436.

Halcón Álvarez Ossorio, Fátima/Herrera García, Francisco Javier/Recio Mir, Álvaro (2009): El retablo sevillano: desde sus orígenes a la actualidad. Sevilla: Fundación Real Maestranza de Caballería de Sevilla, Obra Social de Cajasol y Diputación de Sevilla.

Hall-Van den Elsen, Catherine (2018): Fuerza e intimismo: Luisa Roldán, escultora (1652-1706). Madrid, Consejo Superior de Investigaciones Científicas.

Hernández Díaz, José (1987): Martínez Montañés. Sevilla: Guadalquivir.

Llompart i Moragues, Gabriel (1980): "Imágenes mallorquinas exentas del Niño Jesús”. En: Boletín del Seminario de Estudios de Arte y Arqueología de la Universidad de Valladolid, 46, pp. 363-374.

Llordén, Andrés (1973): Convento de San Leandro de Sevilla (Notas y documentos para su historia). Málaga: Imprenta provincial de Málaga.

López Martínez, Celestino (1932): Desde Martínez Montañés hasta Pedro Roldán. Sevilla: Tipografía Rodríguez, Giménez y Compañía.

Madrazo, Pedro de (1884): España. Sus monumentos y artes. Su naturaleza e historia. Sevilla y Cádiz. Barcelona: Establecimiento Tipográfico-Editorial de Daniel Cortezo y compañía.

Miura Andrades, José María (1999): Frailes, monjas y conventos: las Órdenes Mendicantes y la sociedad sevillana bajomedieval. Sevilla: Diputación Provincial de Sevilla.

Ortiz de Zúñiga, Diego (1796): Anales Eclesiásticos y Seculares de la Muy Noble y Muy Leal, Ciudad de Sevilla. Madrid: Imprenta Real.

Peña Martín, Ángel (2009): "No ai cossa que mas despierte que dormir sobre la muerte. En torno a la imagen del Niño Jesús dormido sobre la cruz del 
convento del Corpus Christi de Valladolid”. En: ¡Aleluya! Revista de la Asociación Belenistas de Valladolid, 4, pp. 28-31.

(2010): "El verme así no te asombre. El Niño Jesús Soberano del Monasterio de Comendadoras de San Juan de Jerusalén de Zamora”. En: Arte y patrimonio de las órdenes militares de Jerusalén en España: hacia un estado de la cuestión. Madrid: Consejo Superior de Investigaciones Científicas, pp. 113-128.

Pleguezuelo Hernández, Alfonso (2008): “Jesús Nazareno de Sisante. Una imagen con historia”. En: Padre Jesús de Sisante, 4, pp. 17-28.

- (2010): "El Niño del Dolor, obra de Luisa Roldán: una confirmación documental". En: Archivo hispalense, 282-284, pp. 501-506.

(2011a): "Los inciertos comienzos de una obra de Luisa Roldán, Jesús Nazareno de Sisante (Cuenca)". En: Fernández Gracia, Ricardo (coord.): Pulchrum. Scripta Varia in Honorem $M^{a}$ Concepción García Gaínza. Pamplona: Gobierno de Navarra y Universidad de Navarra, pp. 634-642.

(2011b): "Cuatro belenes inéditos de la Roldana”. En: Ars Magazine, Revista de arte y coleccionismo, IV, 0, pp. 80-93.

(2012): "Luisa Roldán y el retablo sevillano". En: Laboratorio de Arte, 24, pp. 27-53.

(2016a): "Dos cabezas cortadas atribuibles a Luisa Roldán en la Hispanic Society of America". En: Archivo español de arte, 353, 89, pp. 29-42.

(2016b): "Entre el decoro y la licencia: nuevas obras atribuibles a Luisa Roldán en Zafra (Badajoz)”. En: Laboratorio de Arte, 28, pp. 171-177.

(2016c): "Éxtasis de María Magdalena. Una nueva alhaja de Luisa Roldán”. En: Ars magazine, 33, pp. 66-74.

(2016d): “Los cuatro Reyes Magos de Luisa Roldán”. En: Ars magazine, 30, pp. 106-118.

(2017a): "Luisa Roldán en Sevilla y San José con el Niño Jesús: atribuciones e iconografía". En: Laboratorio de Arte, 29, pp. 377-396.

(2017b): "Ut pictura sculptura. Murillo y la Roldana". En: Navarrete Prieto, Benito (dir.): Murillo y su estela en Sevilla. Sevilla, Ayuntamiento de Sevilla, pp. 27-42.

(2018): "Ternura, dolor y sonrisas. Los sentimientos en la obra de Luisa Roldán”. En: Gila Medina, Lázaro/Herrera García, Francisco Javier (coords.): El triunfo del barroco en la escultura andaluza e hispanoamericana. Granada, Universidad de Granada, pp. 267-288.

Romero Torres, José Luis/Torrejón Díaz, Antonio (coords.) (2007): Roldana. Sevilla, Consejería de Cultura de la Junta de Andalucía.

Sánchez Peña, José Miguel (1985-86): "El Ecce-Homo de la Catedral de Cádiz, obra de Luisa Roldán”. En: Cuadernos de arte de la Universidad de Granada, 17, pp. 329-338. 
Sánchez Peña, José Miguel (1994): "Las tallas de San Servando y San Germán, obras de Luisa Roldán, de la catedral de Cádiz. Nuevos documentos para su historia". En: Anales de la Real Academia de Bellas Artes, 12, pp. 79-106.

Valdivieso González, Enrique/Martínez del Valle, Gonzalo José (2012): Recuperación visual del patrimonio perdido: Conjuntos desaparecidos de la pintura sevillana del los Siglos de Oro. Sevilla: Universidad de Sevilla.

Wethey, Harold (1983): Alonso Cano. Pintor, escultor y arquitecto. Madrid: Alianza Forma. 


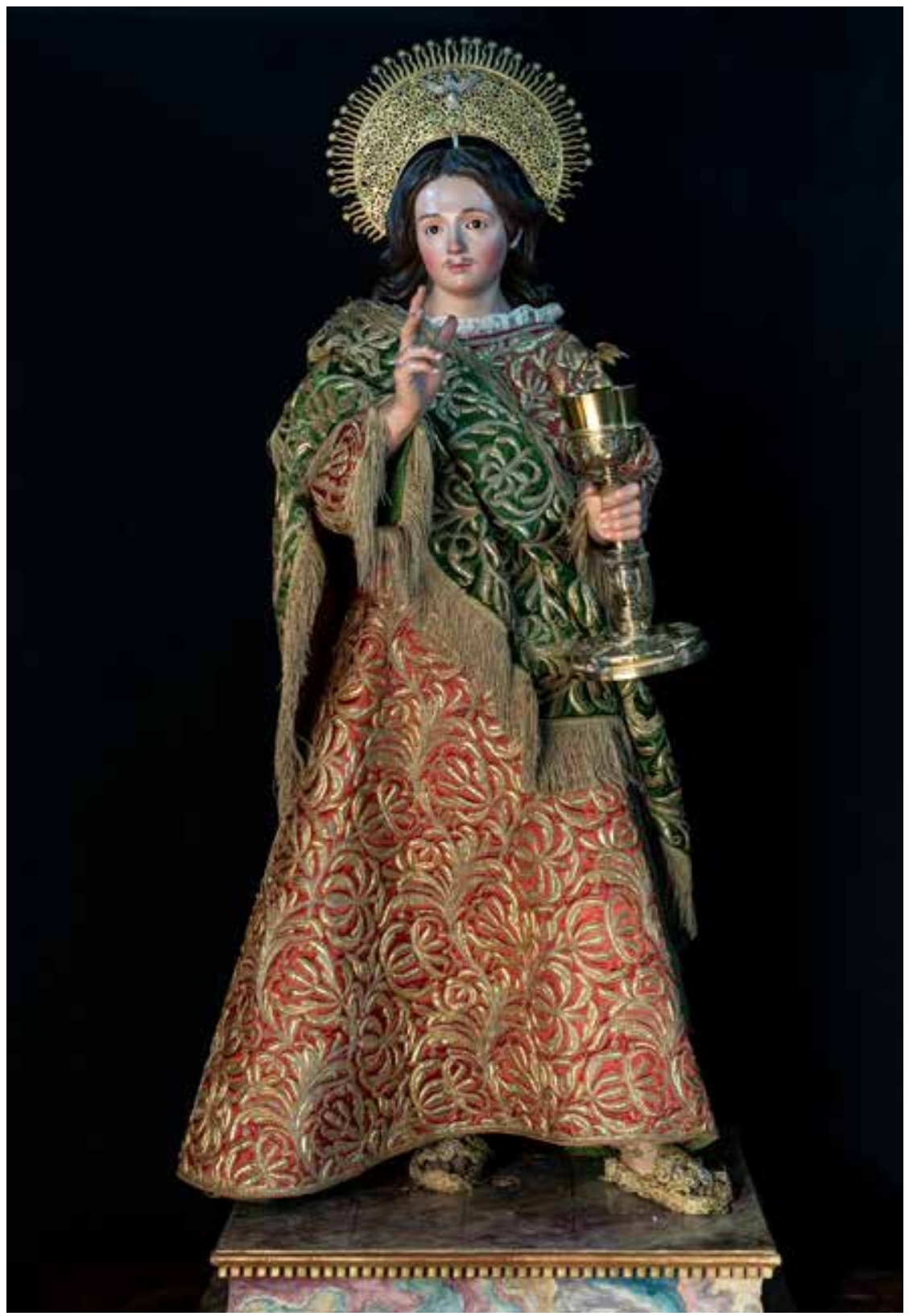

Figura 1. Luisa Ignacia Roldán, San Juan Evangelista, s. XVII, monasterio de San Leandro, Sevilla. Foto: Daniel Salvador-Almeida González. 


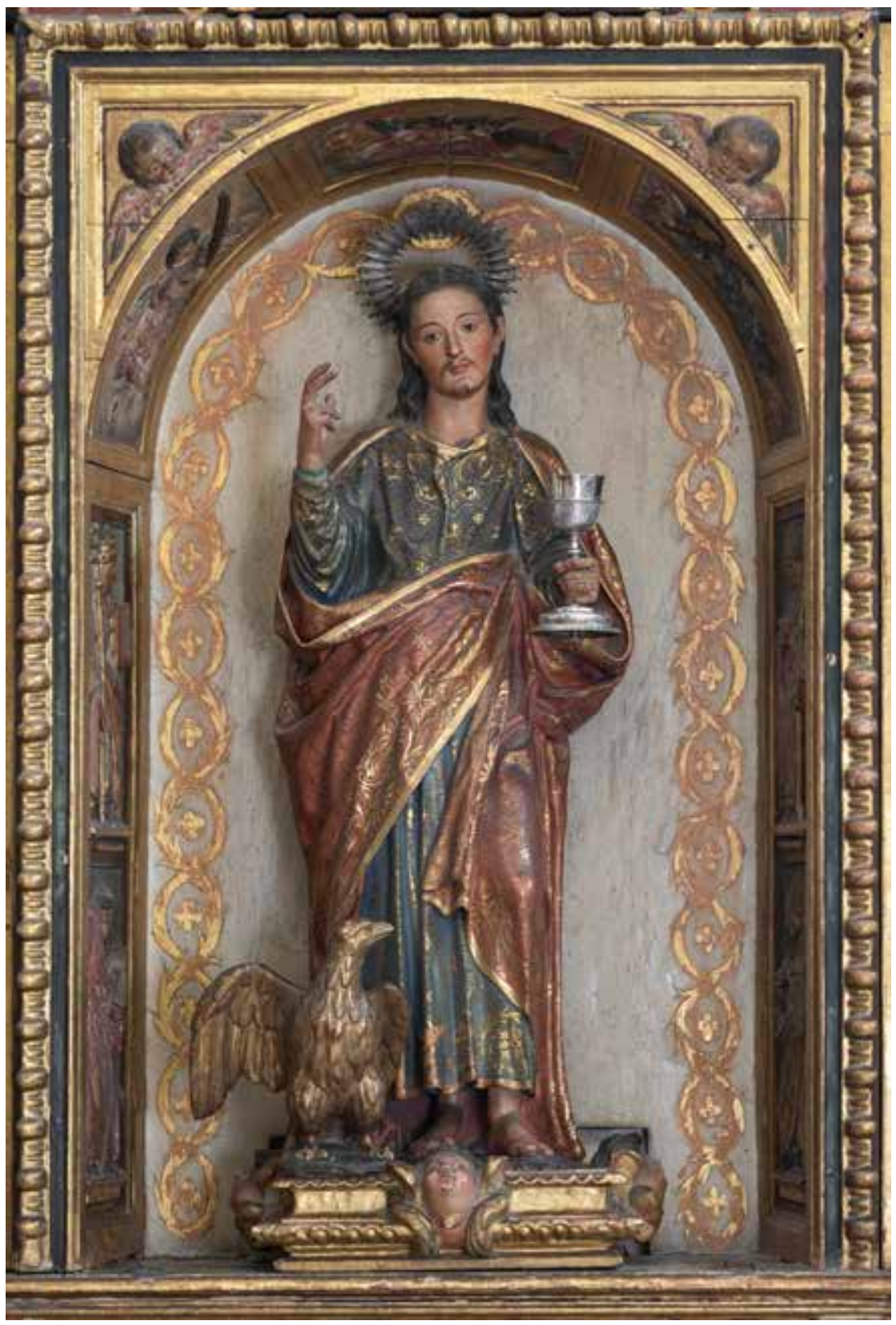

Figura 2. Jerónimo Hernández, San Juan Evangelista, s. XVI, monasterio de San Leandro, Sevilla. Foto: Daniel Salvador-Almeida González. 


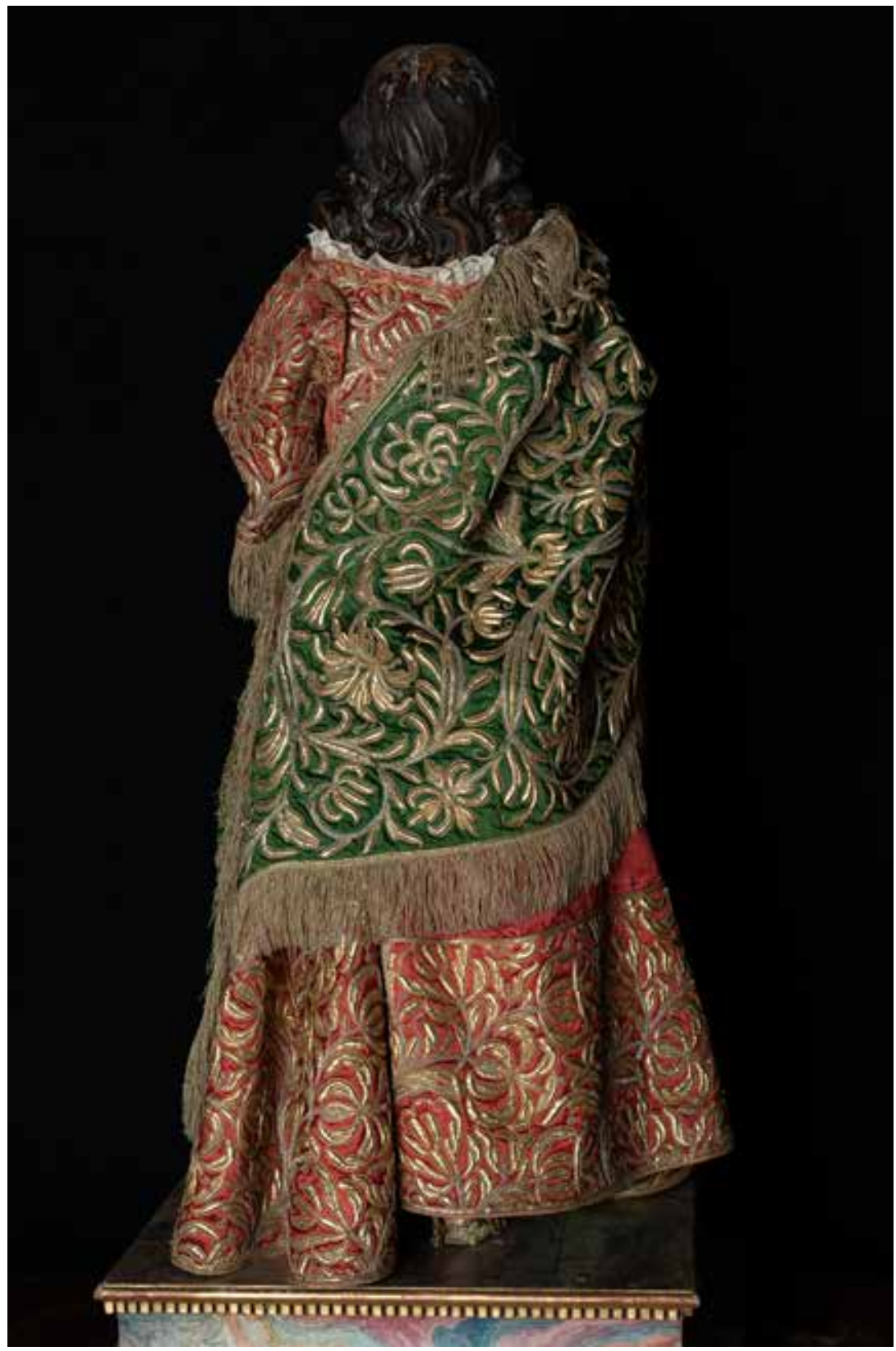

Figura 3. Luisa Ignacia Roldán, San Juan Evangelista, s. XVII, monasterio de San Leandro, Sevilla. Foto: Daniel Salvador-Almeida González.

LABORATORIO DE ARTE 33 (2021), pp. 145-160, ISSN 1130-5762 e-ISSN 2253-8305 - DOI http://dx.doi.org/10.12795/LA.2021.i33.08 


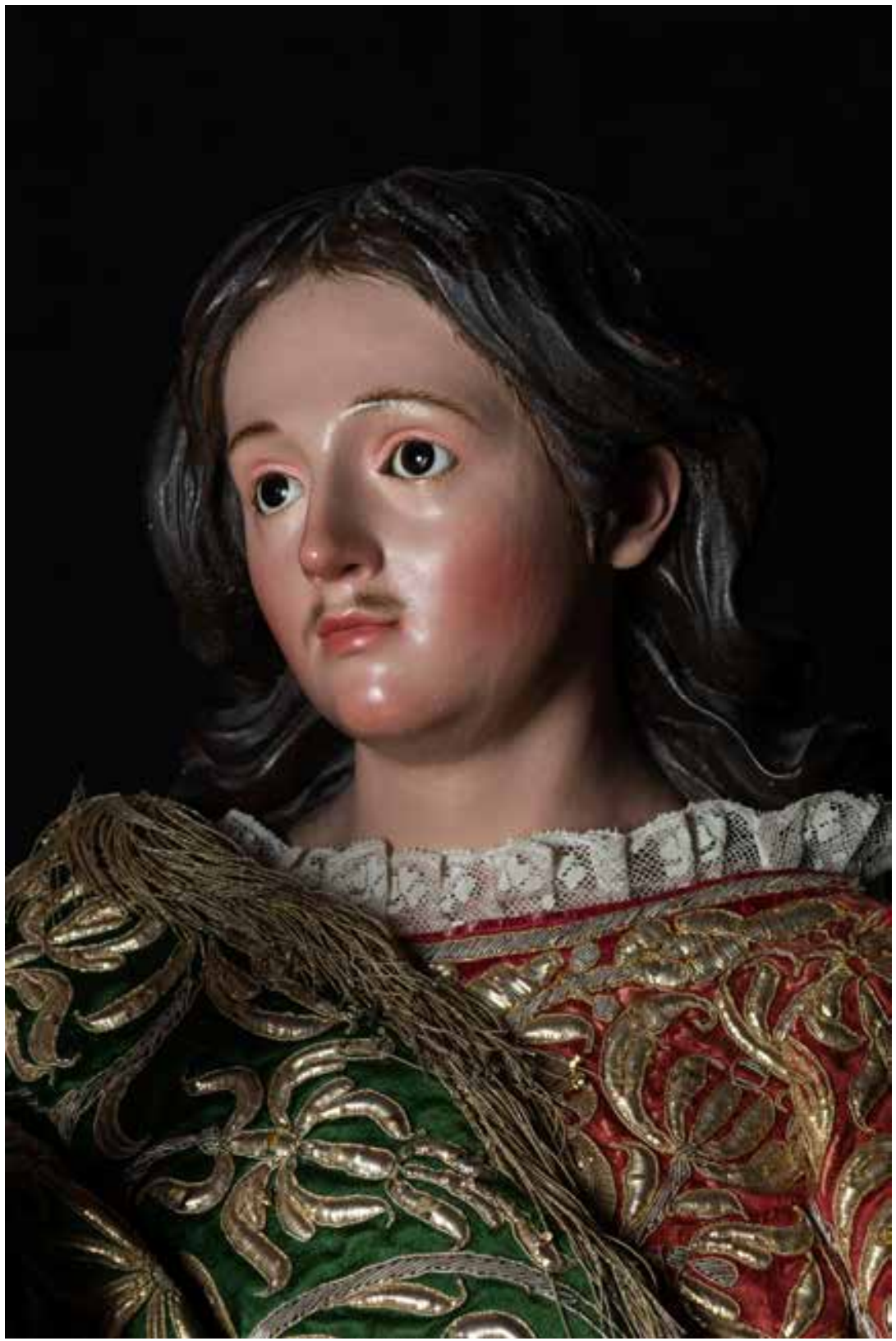

Figura 4. Luisa Ignacia Roldán, San Juan Evangelista, s. XVII, monasterio de San Leandro, Sevilla. Foto: Daniel Salvador-Almeida González. 


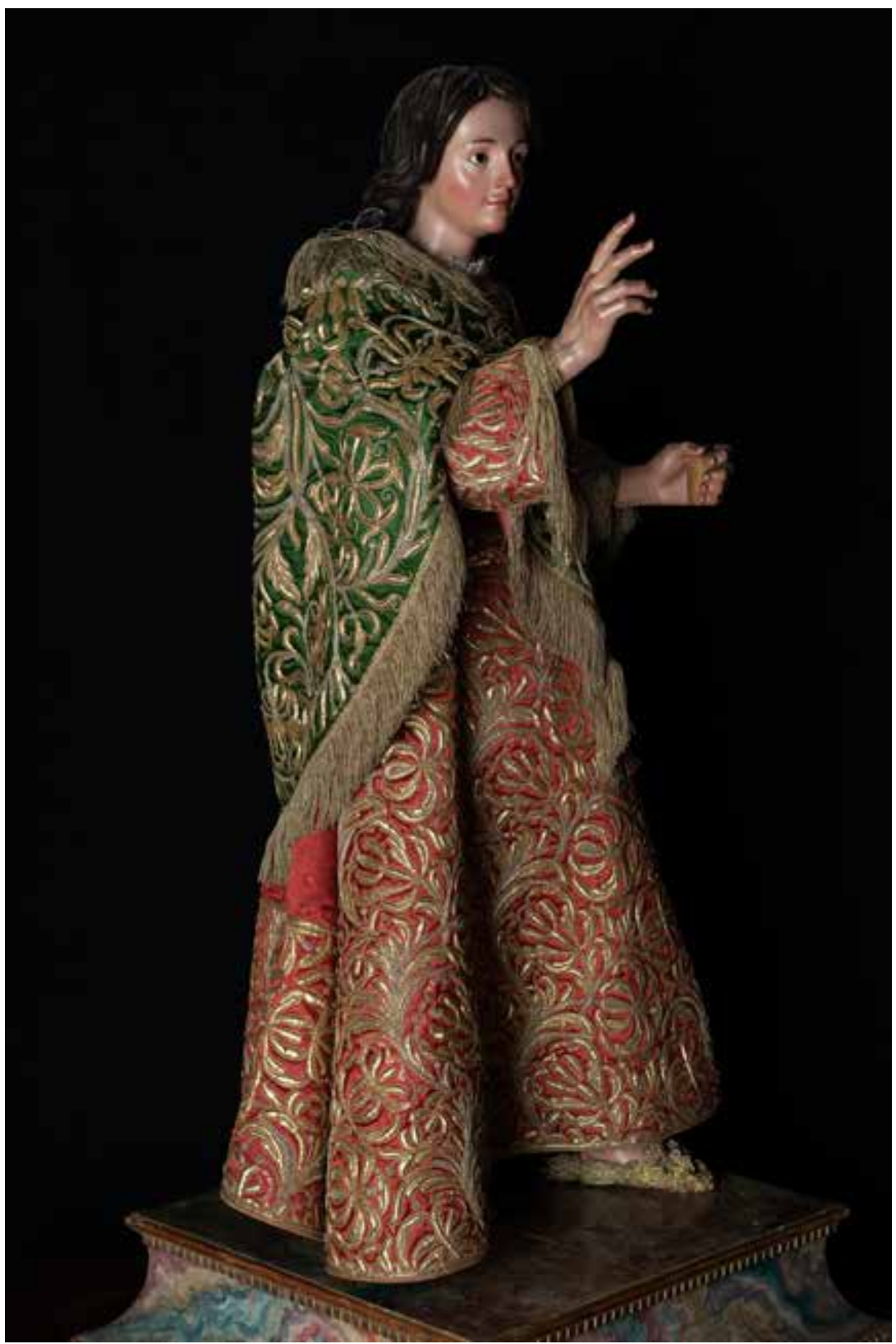

Figura 5. Luisa Ignacia Roldán, San Juan Evangelista, s. XVII, monasterio de San Leandro, Sevilla. Foto: Daniel Salvador-Almeida González. 


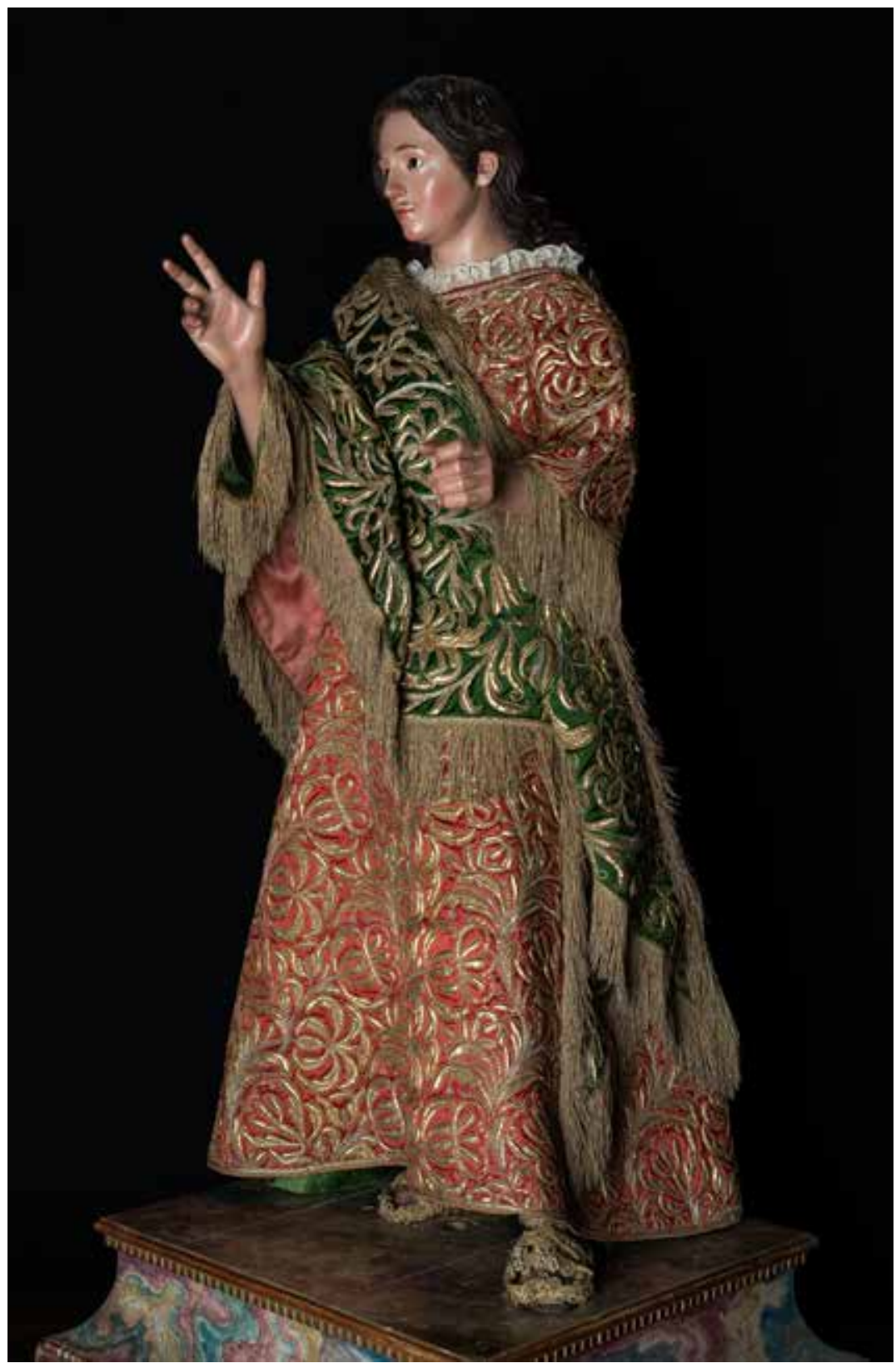

Figura 6. Luisa Ignacia Roldán, San Juan Evangelista, s. XVII, monasterio de San Leandro, Sevilla. Foto: Daniel Salvador-Almeida González. 